\title{
Innovative Methods of Teaching English Language
}

\author{
Mr. G. Anburaj, G. Christopher, Ms. Ni Ming \\ ${ }^{1,2}$ (English, SSL, VIT University, India) \\ 3 (13BCS0153, VIT University, India)
}

\begin{abstract}
This paper analyses the innovative and quite interesting methods we have in teaching English language. We may have a number of teaching methods in between traditional and modern. Everybody has their own understanding and conclusions on teaching English language. But this paper portrays combining this two types how we can make our teaching very effective. We have been completely bounded with traditional methods of teaching and understanding where the present day learners felt uncomfortable a bit. Learner's mind will never be static it is ever growing and ever changing. Whatever the teaching methodology can be, but teaching must be leaner's centred. However, this paper scrutinizes the difference between traditional and practical teaching and thereafter learning. This treatise practically examines that how learners are being affected by the traditional methods of teaching as well, besides it has portrayed that how learners expect teaching and learning process. There has been a misunderstanding between traditional methods and practical methods always. Somehow teachers and learners should agree eachother in order to fill the gap between the generations of these methods.
\end{abstract}

Key Words: Renaissance; orthodox; integral; inquisitive; agitated; jeopardizing; immerse; atmosphere; intuitively; evaluated; database; anagrams; hangman; elocutions; tedious; precautions;

\section{Introduction}

English, the official language of the entire world is a very tricky language to teach. In fact every language varies to teach. English is a very old language and has undergone many forms changes from Proto English derived from the Latin and the German culture to the Modern English which was established after in the post Renaissance period. Each version was simpler than it's previous. Present day English is the simplest adaptation of a very old Language and yet it is still difficult to teach this language effectively especially to those who speak English as a second language.

\section{Problems with current methodologies}

In today's world English is taught in a very orthodox manner. The basic teaching is needed. Teaching the alphabets and the formation of the words is essential and a must. But there is something that is even more important. The children must be able to speak the words and understand their meaning before writing them down. The foundation to teach English can only be taught using the orthodox methods of teaching the alphabets and the words and the rules. But then teaching only the rules is found to be boring by most students and it is because of this that they lose interest in learning the language. Although there is no way other than the traditional one to teach the basics of the language these methods must be tweaked a bit so as to appeal to the students. When it comes to teaching English to students of higher classes who already know the basics the traditional methods generally tend to yield poorer results that innovative methods. This has already been proven by methods implemented like use of stories, poems, movies, books and newspapers etc. These methods help the students learn the language better without them actually realizing and also it keeps their interest. This paper will provide a few of such methods to teach English Language.

\section{Enacting the stories}

Stories form a very integral part of teaching a language. These stories help teach the students about the formation of sentences and how to express their thoughts and a lot of other things and plus they help in keeping the students interest alive as the story's end is something that every student wants to know. It appeals to the inquisitive nature of the students. Any unfinished story always keeps the mind of the reader agitated.

Although this method of using stories has been implemented the procedure of teaching the language through it is generally not right. The evaluation procedure of testing the students in their proficiency over the language is through questions based on the story. This is generally not that effective. Due to this the students generally tend to take up the stories as a chapter rather than looking at it as an interesting read. A story is supposed to appeal to the creative part of the brain. It helps us be more imaginative, by trying to visualize the things that are happening inside the story. It should not only teach them the language but it should also help 
them in extracting a lesson from the story. Keeping questions for evaluation kills the entire idea of imagination for the students look at the story as something that they need to learn for answers.

There is a better way of using the stories to English using stories. The students can enact the stories or the plays. In this way the students are personally engaged with the stories. They can bring their own interpretation of the character to life. It is interesting for the students to understand the characters and put themselves in their positions. It engages their creativity by allowing them to create the entire set, assign the characters and play it out according to what they had imagined. It also helps them understand other people's interpretation of the story and helps them have a healthy conversation about it which again helps them in learning the language. It removes the dull aspects and makes the learning more colourful without jeopardizing the learning of the language. It may not be perfect but it will leave a deep impression on their mind.

The story will help them learn the language as they will be enacting it by dialog which they will themselves extract from the stories and also modifications can be made to the plays to help the students be more interactive and creative. They can add more lines, characters, change the ending, bring in an interesting twist etc. The more creative the modification, more are the points awarded to the team. This also leads to personality development and helps them work as a team player and all the way the student was learning the language.

For example if Julius Caesar was taught using the traditional methods of questions and answers the student would never understand the deep emotions of Brutus, the cunningness of Cassius, the loyalty of Antony, the tragedy of war, the brilliance in Antony's speech and many other such aspects of the story for which the story of Julius Caesar was written by Shakespeare. Similar is the case with all great stories such as Christmas Carol, Harry Potter, and all the epic stories. Emotions help define the story and they form a very important aspect of the language and one's personality. If these emotions are left out then it would be very difficult to express ourselves. On the other hand if such stories are enacted then every intention of the story becomes clear. The students have to immerse themselves into the atmosphere of the story and they have to put them in their positions. This entire process has many benefits besides being a very effective method of teaching the language; it helps preserve the literature, which is nothing but our culture. This method brings about the total learning experience that was meant to be provided by the story and in the end the student will definitely be able to answer questions without even preparing for it as an exam, besides the entire process is fun and not at all boring. Hence it ensures the learning process is complete.

\section{Teaching through conversations}

Conversations are by far the most useful ways of teaching the language. When a child learns his or her mother tongue it is by the conversations that takes place between them and others or by listening to the conversations made by the others. The child is never taught the language but is still able to percept the meaning and learns it automatically to use it in day to day life. No one ever teaches the kid the characters of the language or how to make sentences or the grammar of that language. The conversations alone teach the children.

Hence conversations form a very important part of the teaching process. The sentence construction and the grammar is not something that can be entirely taught by rules. They have to be taught intuitively. That can only happen through a lot of reading and a lot of listening. This can be taken care of easily as every conversation needs a topic. The topic can be given to the students in form of written documents which they have to first read then form an opinion and then have a conversation about it or it can be spoken out and then they can listen, understand and also take part in the conversation.

The participation and other aspects of the conversation can always be evaluated through points which will also push the students to take part in the conversation. These conversations have to be general. They have to happen as if friends are talking to each other. This way the students are comfortable in expressing themselves in the best possible way. This process may take some time but in the end it would be the most efficient one in teaching the language.

\section{Teaching through games}

This is a very interesting method of teaching. Students and children generally tend to like games and want to play them more and more. Traditional methods dictated for study and games to be separate but the fact remains that the students tend to be more interested in playing games rather than sitting down to study. Any logical reasoning would dictate us to combine the two aspects to solve the problem. The games part of learning would help the students keep their interest as the desire to win is very strong. It keeps us going and when included with different aspects of learning the learning process would continue almost throughout the day without the children getting tired or bored of studying.

\section{Word games}

The most important part of any language is the vocabulary. To understand the meaning of the words and to use them in day to day life is a very difficult task and games can help the students overcome this 
difficulty. Games like scrabble, housie etc. have been designed for this specific purpose. These games are just based on words and help the students develop their vocabulary. In addition to these very simple games can be played to help improve the word database of the students such as simple dictation competitions, synonym competitions, words puzzles, anagrams and hangman. All these games are very addictive and help a lot in improving our vocabulary as whenever the student hears a new word the first question that comes up is "what is its meaning?" and in this way the vocabulary improves and most of the times we don't even have to consult the dictionary.

\section{Competitions}

Most of the times competitions like debates and elocutions also help the help the students a lot in learning the language as the aspect of the competitions keep them at the best in conversations. It forces them to use the best possible construction of sentences to put forward their opinions and to use good vocabulary etc. This is a very important tool in helping them learn the language. Also these competitions help them address large crowds which is again is a very important part of personality development.

\section{Creative assignments}

Up till now most of the techniques that we discussed required a greater amount of effort on the student's part. This method requires effort on the teacher's part. Assignments help the students learn something on their own and most of the times they have to research on something then write something up on it. This method although effective is most of the times very tedious. This method of approach is very appropriate for sciences and engineering although when it comes to languages the students should be given assignments in which they have to modify something that already exists.

If the students are just given assignments like 'write a story or a poem or a report' then most of the students crack because not everyone can come up with a story or even if they come up with one they cannot write it down. In such case the students should be given the base knowledge and data and then ask them to modify the data for example the students can be given a base story and then ask them to modify a part of it. This engages their creativity and also helps them overcome their difficulty of writing. Above all it lifts the pressure of creating completely new. Invention is very difficult especially when we are being forced to do it. In this way the students are not forced to complete the assignment and then they can do it whole heartedly and hence complete the learning experience that can be gained from the assignment.

\section{Help from the multimedia}

Multimedia sources like songs, movies, TV series, magazines, newspapers play a very vital role in improving our language. We don't even realize that they have helped us. We just wake up one fine day and realize that we are better than it than we were yesterday. Such sources can be used to help the students improve their language. But great precautions must be taken. This method should be used in the final stages of learning as that is the only place where there is no scope of damage as most of the movies and songs etc. use colloquial English most of the times which is grammatically wrong and it is very important that the students understand that fact so that they do not use that form of the language in their everyday usage.

Apart from that this source is very helpful as it does not feel like education. This is something that the students will do in their spare time. The songs are the best way to communicate how to use a language to express our feelings. Movies are a very common past time but apart from that most of the times they are also very instructional and educational. Also this method appeals to the students as most of the times they are able to connect with the songs and the movies which help them understand the meaning of expressions, usage of tools of the language like comparisons, personifications etc. These sources help them understand why such tools are necessary and also help them understand their usage. Hence this method is again very effective in teaching the language. Traditional methods of reading newspapers and books, novels are also very good methods to teach the language. When the traditional methods are modified along with some innovative ideas the entire learning and the teaching process is enriched and guarantees a success in efficient learning. These are some of the innovative and creative ways of teaching the English Language.

\section{Conclusion}

The languages play a very important role in our lives. They help us express our emotions. They help us explain what we want. They help us to communicate and hence are the prime tools to express who we are. Thus the knowledge of a language and its proper utilization is very important as it defines us. If languages were not there to help us communicate there would be no difference in our communications and the way the animals communicate. Hence the ways the languages are taught play a very vital role in a person's life.

Since English is the official language of this world it is of utmost importance that this language has to be taught in such a way that it will help us not just to speak and write and listen but to communicate. That is the 
purpose of the language and that is what it must be used for. Hence innovative methods help in bringing a change and most of the times for the better. It helps the students learn faster and in an efficient, interesting and an interactive manner and it is the teacher's responsibility to leave the traditional methods and make way for new and better methods for the students benefit.

\section{Acknowledgement}

I have taken efforts in this research paper. However, it would not have been possible without the kind support and help of many individuals. I would like to extend my sincere thanks to all of them. My thanks and appreciations also go to my colleagues in developing and concluding this precise research and students who have willingly helped me out with their abilities. The take this opportunity which I had with my learners in our VIT University was a great chance for learning and professional development. Therefore, I consider myself as a privileged individual as I was provided with an opportunity to be a part of it this study. I am also grateful for having a chance to meet so many wonderful students and faculty members who led me throughout this research paper in order to shape the core idea.

Bearing in mind the above, I am using this opportunity to express my deepest gratitude and special thanks to Prof. G. Christopher, (Assistant Professor) one of the co-authors of this study who in spite of being extraordinarily busy with his work, took time out to hear, share and keep me on the correct path and allowing me to carry out my ideas neither changing nor deviating from it.

It is my radiant sentiment to place on record my best regards, deepest sense of gratitude to Ms. Ni Ming, (13BCS0153), who is one of the co-authors, for her careful and tireless proof reading, alignments, valuable suggestions and clear insights regarding the key factors of this paper which were extremely valuable for my study both theoretically and practically. This paper is one of the evidences of her interest over English language learning and manipulating. I would like to express my special thanks of gratitude to my co-authors for their contribution on the introduction of main ideas, conclusion and minute details in order to focus the core objectives of this research paper is really undeniable.

Finally I dedicate my priceless thanks and regards to our division chairs, dean, administration and management teams of VIT University, without their support and encouragement, this research wouldn't have been carried out successfully.

\section{Work cited}

[1]. Kevin D. Besnoy, Lane W. Clarke, High-Tech Teaching Success! A Step-by-Step Guide to Using Innovative Technology in Your Classroom, Prufrock Press, Inc. October 1, 2009

[2]. Lynne T. Diaz-Rico, Teaching English Learners: Strategies and Methods Marlene D. LeFever, Creative Teaching Methods, Cook Ministry Resources; March 1, 1997

[3]. Edgar H. Schuster, Edgar H. Schuster, Breaking the Rules: Liberating Writers Through Innovative Grammar Instruction, Heinemann; February 13, 2003

[4]. Nicholas McGuinn,David Stevens, The Art of Teaching Secondary English: Innovative and Creative Approaches, Routledge; August 7, 2004

[5]. Paul Nation, New Ways in Teaching Vocabulary (New Ways in Tesol Series: Innovative Classroom Techniques); TESOL, January 1,1995

[6]. R. Patrick Solomon, Dia N. R. Sekayi, Urban Teacher Education and Teaching: Innovative Practices for Diversity and Social Justice, Routledge; March 30, 2007

[7]. Patrick Schwarz, Paula Kluth You're Welcome: 30 Innovative Ideas for the Inclusive Classroom; Heinemann, August 17, 2007

[8]. Constance Leuenberger, The New Kindergarten: Teaching Reading, Writing, \& More, Publisher: Teaching Resources, August 11, 2003

[9]. Judith S. Gould, Evan Jay Gould, Judy Mitchell, Mary Rojas, Four Square Writing Method : A Unique Approach to Teaching Basic Writing Skills for Grades 1-3,

[10. ]Martha Bradshaw, Arlene Lowenstein, Innovative Teaching Strategies in Nursing and Related Health Professions; Jones \& Bartlett: March 8, 2010

[11]. Susan Van Zile, Awesome Hands-on Activities for Teaching Grammar, Teaching Resources; December 1, 2003 